\title{
Expressão gênica diferencial em genótipos de mamona (Ricinus communis L.) submetidos a déficit hídrico induzido por PEG
}

\author{
Patrícia Favoretto Moraes ('); Daiane Mariele De Laat ('); Marina Erê Almeida Hummel Pimenta \\ Santos ( $\left.{ }^{1}\right)$; Carlos Augusto Colombo $\left({ }^{1 *}\right)$; Tammy Kiihl ( $\left.{ }^{2}\right)$ \\ (') Instituto Agronômico (IAC), Centro de Recursos Genéticos Vegetais, Avenida Barão de Itapura, 1.481, 13012-970 Campinas (SP), \\ Brasil. \\ (2) Embrapa Trigo, Caixa Postal 451, 99001-970 Passo Fundo (RS), Brasil. \\ (*) Autor correspondente: ccolombo@iac.sp.gov.br
}

Recebido: 24/jul./2014; Aceito: 8/out./2014

\begin{abstract}
Resumo
A mamoneira é uma cultura de relevância econômica e social no Brasil e no mundo. O óleo produzido por suas sementes, composto principalmente pelo ácido ricinoleico, é estratégico para as indústrias de lubrificantes, cosméticos, polímeros, dentre outras. Embora a mamoneira seja considerada tolerante à seca, a ausência de chuvas no período da floração pode reduzir a produtividade da planta. Respostas diferenciais ao déficit hídrico na espécie têm sido observadas em acessos de bancos de germoplasma e entre cultivares comerciais. Com intuito de conhecer melhor os mecanismos fisiológicos de resposta ao déficit hídrico e direcionar programas de melhoramento genético, o objetivo do trabalho foi analisar a expressão diferencial de genes potencialmente relacionados com a tolerância da mamoneira ao déficit hídrico e o comportamento de enzimas do sistema de defesa antioxidante. O estudo foi conduzido com três acessos (China Careca, IAC 2028 e PB 07) submetidos a um ensaio com solução de polietilenoglicol (PEG 6.000) por um período de 24 horas para indução do déficit hídrico. Os genes CAT, APX, SOD-Cu/Zn, SOD-Fe e SOD-Mn tiveram maior expressão diferencial no acesso China Careca. O gene SOD-Cu/Zn foi o mais diferencialmente expresso quanto comparado ao controle (3,57 vezes) no acesso China Careca. Análise da atividade de enzimas relacionadas com estresse oxidativo (Catalase - CAT, Ascorbato Peroxidase - APX, Guaiacol Peroxidase - GPOX e Superoxide Dismutase - SOD) revelou que os acessos possuem diferentes mecanismos de resposta ao déficit hídrico. Os resultados apontam que o acesso China Careca pode ser considerado de grande importância para programas de melhoramento genético por apresentar característica de precocidade, sistema de defesa antioxidante mais eficiente e resistência ao déficit hídrico.
\end{abstract}

Palavras-chave: Ricinus communis L., estresse oxidativo, enzimas antioxidantes, expressão gênica, PCR quantitativo em tempo real (q-PCR).

\section{Genes differentially expressed in castor bean genotypes (Ricinus communis L.) under water stress induced by peg}

Abstract

Castor bean is a crop of social and economic importance in Brazil and worldwide. The oil produced from its seeds, comprised mainly of ricinoleic acid, is strategic for the manufacture of lubricants, cosmetics, polymers, among others. Although castor bean is considered drought tolerant, the lack of rain during flowering can reduce plant yield. Differential responses to drought in the species have been observed in the genebank accessions and between cultivars. In order to better understand the physiological mechanisms of response to water deficit and direct breeding programs, the objective was to analyze the differential expression of genes potentially related to tolerance to water deficit in castor bean and the behavior of enzymes of the antioxidant defense system. The study was conducted with three accessions (China Careca, IAC 2028 and PB 07) subjected to a test solution with polyethylene glycol (PEG 6.000) for a period of 24 hours for induction of drought. CAT, APX, SOD-Cu/Zn, Fe-SOD and Mn-SOD genes had higher differential expression in China Careca accession. The SOD-Cu/Zn gene was the most differentially expressed in China Careca access when compared to control (3.57 times). Analysis of the activity of enzymes related to oxidative stress (catalase - CAT, ascorbate peroxidase - APX, Guaiacol Peroxidase and Superoxide Dismutase-GPOX activity-SOD) revealed that the accessions have different mechanisms of response to water deficit. The results indicate that China Careca accession can be considered of great importance for breeding programs by presenting precocity characteristic, more efficient antioxidant defense system and resistance to drought.

Key words: Ricinus communis L., oxidative stress, antioxidant enzymes, gene expression, quantitative real time PCR (Q-PCR). 


\section{INTRODUÇÃO}

A mamoneira (Ricinus communis L. - Euphorbiaceae) é uma cultura com destacada aplicaçáo industrial por apresentar mais de $85 \%$ de ácido ricinoleico no óleo de suas sementes, o que the confere índice de viscosidade mais elevado e maior estabilidade entre todos os óleos vegetais, combinados com alta lubricidade, especialmente sob condiçóes de baixa temperatura, notadamente para fabricação de gasolina de aviação, lubrificantes, nylon, corantes, tintas, sabōes, adesivos e biodiesel (Ogunniyi, 2006).

Há registros muito antigos de ocorrência da mamona no sudeste do Mediterrâneo, África Oriental e Índia, sendo mais provável que tenha se originado na África tropical (Weiss, 1971). A distribuição da espécie nos dias de hoje ocorre entre as latitudes $40^{\circ}$ Norte e $40^{\circ}$ Sul, sendo cultivada em mais de 15 países (Allan et al., 2008; Figueiredo et al., 2004), particularmente na Índia, China e Brasil (Atsmon, 1989).

A mamoneira é uma planta perene com variação no hábito de crescimento, cor da folhagem e caules, tamanho da semente e teor de óleo (Weiss, 2000). Geralmente considerada tanto de auto como de polinizaçáo cruzada pelo vento, estudos de cruzamento controlados sugerem que a polinização cruzada é um modo frequente de reprodução e que a taxa de alogamia natural pode ser superior a 40\% (Brigham, 1967).

A mamoneira é tida como tolerante à seca, provavelmente devido ao sistema radicular bem desenvolvido. Há referências de bons rendimentos com chuvas de 375 a $500 \mathrm{~mm}$ anuais (Weiss, 1983). Porém, embora tolerante à seca, tanto a ausência como o excesso de chuvas no período da floração podem reduzir a produtividade da planta e a falta de água, nessa última fase, pode comprometer a formação de frutos (Souza et al., 2007).

A seca é um fator importante que afeta o desenvolvimento das plantas, prejudicando o rendimento das culturas em geral. Essa condição induz um conjunto de respostas fisiológicas, bioquímicas e moleculares, as quais desenvolvem habilidades para adaptação às circunstâncias ambientais limitantes, dependendo da intensidade e da duraçáo do estresse, dos efeitos interativos de outros tipos de estresse, do estádio de desenvolvimento e do genótipo (Meneses et al., 2006). O impacto da seca na agricultura é uma importante consequência socioeconômica que afeta milhôes de pessoas ao redor do mundo (Elliott et al., 2013). Para sobreviverem na falta de água, as plantas desenvolveram mecanismos de tolerância. Tolerância à seca é considerada uma característica poligênica e difícil de ser trabalhada no melhoramento genético clássico (Beever, 2000). Assim, a biologia molecular é considerada uma ferramenta de extrema importância na identificação de genes envolvidos nas respostas ao déficit hídrico. Em genótipos de soja tolerantes a seca o gene NADH desidrogenase foi diferencialmente expresso durante período de seca, associado com rotas metabólicas que podem estar envolvidas em respostas ao déficit hídrico (Casagrande et al.,
2001). O estresse hídrico provoca alterações na expressão gênica de diferentes categorias funcionais. Observou-se em feijão-caiupi a indução de genes pertencentes à biossíntese de ácido abscísico, sinalização celular, transportador de prolina e biossíntese de lipídeos de membranas. A expressão desses genes indica sua participação em processos relacionados à proteçâo da planta ao estresse abiótico (Silva et al., 2012). Sob estresse, as plantas produzem espécies reativas de oxigênio (ERO), que são moléculas instáveis e extremamente reativas capazes de transformar outras moléculas com as quais colidem, afetando moléculas como proteínas, carboidratos, lipídeos e ácido nucleicos (Silva \& Gonçalves, 2010).

Alguns trabalhos têm mostrado que o déficit hídrico ativa o sistema de defesa enzimático das plantas para eliminação das espécies reativas de oxigênio ou ERO (Fan et al., 2009; Jaleel et al., 2007; Jambunathan, 2010; Jebara et al., 2005). Esse fato ocorre devido a alteraçóes no metabolismo das plantas. Essas formas reativas de oxigênio, como Peróxido de Hidrogênio $\left(\mathrm{H}_{2} \mathrm{O}_{2}\right)$, Radical Superóxido $\left(\mathrm{O}_{2}{ }^{-}\right)$e Radical Hidroxila $\left(\mathrm{OH}^{-}\right)$, são conhecidas por oxidar importantes constituintes celulares, tais como: ácidos nucleicos, lipídeos de membrana (camada bipolar) e proteínas, podendo ocasionar a morte celular (Alscher et al., 2002). A produçáo das enzimas como: Catalase (CAT), Ascorbato Peroxidase (APX), Guaiacol Peroxidase (GPOX) e Superoxide Dismutase (SOD) é essencial para a eliminação das ERO presentes nas células. Dessa forma, o aumento na atividade das enzimas do sistema antioxidante é importante para eliminar o acúmulo de $\mathrm{H}_{2} \mathrm{O}_{2}$ e assim reduzir a peroxidação de lipídios (Eyidogan $\& \mathrm{Oz}, 2007$; Vaidyanathan et al., 2003).

$\mathrm{O}$ aumento da demanda de mamona em muitos países vem atraindo grande atenção de melhoristas dos países produtores (Sujatha et al., 2008). Compreender o sistema antioxidativo das plantas é fundamental para a seleção de acessos que apresentam menor sensibilidade ao déficit hídrico e maior tolerância à seca. Informaçôes básicas sobre o entendimento do mecanismo de resposta ao déficit hídrico poderão representar importante avanço ao desenvolvimento de cultivares resistentes ao déficit hídrico, haja vista que a planta vem sendo cultivada em regióes de baixos níveis de precipitação em muitos países.

\section{MATERIAL E MÉTODO}

Inicialmente, foi conduzido um experimento com seis acessos de Ricinus communis expostos a diferentes concentraçôes de polietilenoglicol (PEG 6.000) para determinação de curva de resposta. Três acessos foram selecionados para o estudo em funçáo de respostas divergentes de tolerância e susceptibilidade à exposição ao estresse hídrico induzido por $10 \mathrm{gL}^{-1}$ de PEG: IAC 2028 (cultivar comercial), PB 07 (linhagem avançada) e China Careca (acesso não 
melhorado). A concentraçáo de $10 \mathrm{~g} \mathrm{~L}^{-1}$ de $\mathrm{PEG}$ possui o potencial hídrico de 0,006095 MPa.

Sementes dos três acessos foram germinadas em papel de filtro em incubadora mantida a $25^{\circ} \mathrm{C}$. Após sete dias, as mudas foram transplantadas para vasos com vermiculita e mantidos em casa de vegetação sob irrigação. Após 30 dias, as plântulas, com aproximadamente $15 \mathrm{~cm}$ de altura, foram transferidas para ambiente climatizado em tubos de $50 \mathrm{~mL}$ contendo água destilada (controle) e em tubos de $50 \mathrm{~mL}$ contendo PEG $6.00010 \mathrm{~g} \mathrm{~L}^{-1}$ (tratamento), nas condiçôes de crescimento de 12 horas de luz e $25^{\circ} \mathrm{C}$ constantes. Os tratamentos foram aplicados durante 24 horas e as amostras foram coletadas nos tempos de 2, 8 e 24 horas. Para cada tratamento foram adotadas três repetiçóes biológicas.

\section{Isolamento de RNA e síntese de DNA complementar}

O RNA total foi extraído a partir de $50 \mathrm{mg}$ de folhas frescas usando-se o reagente Trizol (Invitrogen), de acordo com as instruçôes do fabricante. A qualidade e a concentração do RNA extraído foram avaliadas através de espectrofotometro Nano-Drop (ND-1.000) (NanoDrop Technologies, Wilmington, DE, EUA). A contaminação por fenol, hidratos de carbono e proteínas foi determinada com base nos índices de OD, A260/A230 e A260/A280, respectivamente, considerando-se apenas as amostras com razão maior que 1,7. A fim de verificar a integridade do RNA, as amostras foram separadas por electroforese num gel de agarose $1 \%$ corado com Gel Red (Biotium, Hayward, CA, EUA) e visualizadas com um HP AlphaImager (Alpha Innotech Corporation, Santa Clara, CA, EUA). Contaminantes de DNA e pequenos RNA foram eliminados com GeneJET ${ }^{\mathrm{TM}}$ RNA Purification Kit (Thermo Scientific).

A primeira fita de cDNA foi sintetizada a partir de $8 \mu \mathrm{L}$ de RNA total em uma reação de $20 \mu \mathrm{L}$ utilizando-se RevertAid H Minus First Strand cDNA Synthesis Kit (Thermo Scientific). Os cDNAs foram diluídos para $5 \mathrm{ng} \cdot \mu \mathrm{L}^{-1}$

Foi feita uma análise in silico para a seleção de sequências de SOD, Catalase, Ascorbato Peroxidase usando EST (expressed sequence tags) de mamona do NCBI (National Center for Biotechnology Information). Cinco oligonucleotídeos iniciadores específicos foram desenhados: um para Catalase (CAT), um para Ascorbato Peroxidase (APX) e três para as isoformas Superóxido Dismutase (SOD-Fe, SOD-Cu/Zn e SOD-Mn), usando Primer3 software (Rozen \& Skaletsky, 2000). Os iniciadores de referência foram ubiquitina (UBT) e actina (ACT) (Morgante et al., 2011). Foi realizado um experimento de validação para confirmar a eficiência da PCR. As curvas de calibração para cada iniciador foram geradas utilizando-se diluições do cDNA em água para $10 \mathrm{ng} ; 5 \mathrm{ng}$; 2,5 ng; 1,25 ng; 0,625 ng; 0,312 ng; e 0,156 ng e a eficiência de amplificação calculada por $\mathrm{E}=\left(10^{-1 / \text { lope }}-1\right) \times 100$.
Para a análise de expressão foi utilizado PCR em tempo real quantitativo (qPCR). Os níveis de expressão de mRNA foram avaliados num ensaio de SYBR Green utilizando um Applied Biosystems 7.500 Fast Real-Time PCR System (Applied Biosystems, CA, EUA). As amplificaçōes de PCR foram realizadas em triplicata em reaçóes de $20 \mu \mathrm{L}$ contendo Maxima SYBR Green/qPCR ROX Mix Master (Fermentas), $250 \mathrm{nM}$ de cada iniciador (direto e inverso) e 4 ng de cDNA. As condiçóes de amplificação foram de $50{ }^{\circ} \mathrm{C}$ durante $2 \mathrm{~min}, 95^{\circ} \mathrm{C}$ durante $10 \mathrm{~min}, 40$ ciclos a $95^{\circ} \mathrm{C}$ durante $15 \mathrm{~s}, 60^{\circ} \mathrm{C}$ durante $1 \mathrm{~min}$. Para verificar a especificidade de amplificação foi adicionado um estágio de curva de dissociação. Em cada placa, genes de referência (actina e ubiquitina) e controle negativo foram incluídos.

\section{Determinação da expressão diferencial}

Valores de Ct (Cycle Threshold) foram determinados utilizando-se o software SDS (Applied Biosystems, CA, EUA). Dados de expressáo gênica foram avaliados utilizando-se os valores Ct e de eficiência de amplificação, usando o método $2^{-\Delta \Delta C}$ (Livak \& Schmittgen, 2001). O Heat map foi construído utilizando-se o programa JColorGrid (Joachimiak et al., 2006).

\section{Avaliação da atividade enzimática}

As atividades enzimáticas foram determinadas em espectrofotômetro (Thermo scientific GENESYS 10S/UV).

Para a determinaçáo da atividade enzimática das enzimas CAT, GPX e APX, folhas foram maceradas em tampão fosfato $100 \mathrm{mM}$.

A atividade da CAT foi determinada em $100 \mu \mathrm{L}$ de extrato enzimático, $2.000 \mu \mathrm{L}$ de tampão fosfato de potássio $100 \mathrm{mM}$ e $1,5 \mu \mathrm{L}$ de peróxido de hidrogênio $\left(\mathrm{H}_{2} \mathrm{O}_{2}\right) 30 \%$, observando-se o decréscimo de $\mathrm{H}_{2} \mathrm{O}_{2}$ a $240 \mathrm{~nm}$, de acordo com o método de Costa et al. (2005).

Para a atividade enzimática da GPX foi utilizado $100 \mu \mathrm{L}$ de extrato enzimático, $2,9 \mathrm{~mL}$ de tampão fosfato de potássio $100 \mathrm{mM}, 15 \mu \mathrm{L}$ de $\mathrm{H}_{2} \mathrm{O}_{2} 2 \%$ e $15 \mu \mathrm{L}$ de Guaiacol 0,05\%, observando-se o acréscimo de Guaiacol a $470 \mathrm{~nm}$, de acordo com método de Costa et al. (2005).

A atividade da APX foi obtida com a adição de $100 \mu \mathrm{L}$ de extrato enzimático, 2,9mL de tampão fosfato de potássio $100 \mathrm{mM}, 30 \mu \mathrm{L}$ de EDTA $10 \mathrm{mM}, 30 \mu \mathrm{L} \mathrm{H}_{2} \mathrm{O}_{2} 100 \mathrm{mM} \mathrm{e}$ $30 \mu \mathrm{L}$ de ácido ascórbito $50 \mathrm{mM}$, observando-se o decréscimo de ácido ascórbico a $290 \mathrm{~nm}$, de acordo com o método de Amako et al. (1994).

Para a determinação da atividade enzimática da enzima SOD, as folhas da mamona foram maceradas num tampão fosfato de potássio $50 \mathrm{mM}$ (1 mL tampão fosfato de potássio 0,5 M, $9 \mathrm{~mL} \mathrm{H}_{2} \mathrm{O}$ e 20 ul EDTA 5 mM, 0,1 g PVPP). 
A atividade de SOD foi determinada por espectrofotometria, de acordo com o método de Gupta et al. (1993), com algumas modificaçôes, por meio de uma solução contendo $20 \mu \mathrm{L}$ de extrato enzimático, $700 \mu \mathrm{L}$ de tampão fosfato de potassio $50 \mathrm{mM}, 40 \mu \mathrm{L}$ de metionina $500 \mathrm{mM}, 30 \mu \mathrm{L}$ de azul de nitrotetrazólio (NTB) $1 \mathrm{mM}, 50 \mu \mathrm{L}$ de triton X-100 (0,5\%) e $176 \mu \mathrm{L}$ de riboflavina.

O cálculo da atividade enzimática de CAT, APX, GPOX foi determinado pela fórmula:

Atividade enzimática $=(\Delta \text { leitura } / \text { c.e })^{*}(\Delta \text { tempo } / 1.000)^{*}($ volume cubeta $) *(1 / \text { extrato enzima })^{*}(\text { volume tampão })^{*}($ volume tampão/volume tampão após centrifugação $)^{*}(1 /$ gramas de tecido).

Em que c.e é o coeficiente de extinção molar de cada enzima $\left(\mathrm{CAT}=39,4 \mathrm{mM}{ }^{-1} \cdot \mathrm{cm}^{-1}, \mathrm{APX}=2,8 \mathrm{mM}^{-1} \cdot \mathrm{cm}^{-1}\right.$, GPOX $\left.=26,6 \mathrm{mM}^{-1} \cdot \mathrm{cm}^{-1}\right)$.

Como a enzima SOD não apresenta coeficiente de extinçáo molar, foi utilizada a mesma fórmula apresentada para as outras enzimas. Porém, esse coeficiente foi substituído pelo valor da diferença de leitura entre os extratos controle e tratamento.

As atividades catalíticas das enzimas foram calculadas de acordo com as absorbâncias obtidas e expressas em $\mu$ mol. $\mathrm{min}^{-1}$. $\mathrm{mg}^{-1}$.MF.

\section{Análise de dados}

A análise de variância (ANOVA) dos dados bioquímicos foi feita usando o programa R (R Development Core Team, 2011) comparando os valores médios de tratamentos e controles, e as diferenças entre valores médios do tratamento menos controle $(\Delta=$ Tratamento-Controle). Os valores encontrados foram comparados pelo teste de Tukey $(\mathrm{p}<0,05)$.

\section{RESULTADOS}

\section{Expressão diferencial}

Os iniciadores desenhados e os genes de referência actina e ubiquitina foram selecionados a partir do teste de eficiência de amplificaçấo (Tabela 1). Os valores de eficiência de amplificaçáo dos genes alvos e normalizadores variaram de 0,96 (CAT) a 1,11 (ACT), aproximadamente $100 \%$ para os oligonucleotídios iniciadores escolhidos, considerados valores ideais (Pfaffl, 2001) para o sucesso da técnica.

Para a análise da expressão diferencial foram considerados como diferencialmente expressos os genes cujos valores de quantificação relativa $(\mathrm{QR})$ foram superiores a $1,5(\mathrm{QR}>1,5)$ após indução de déficit hídrico por PEG.

A análise de variância mostrou que apenas no tempo 24 horas houve diferença significativa de expressão entre os acessos. Por esse motivo, as amostras analisadas foram aquelas coletadas no período de 24 horas.
O cálculo de QR para os tratamentos (PEG $6.00010 \mathrm{~g} \mathrm{~L}^{-1}$ ) das moléculas alvo nas amostras dos acessos IAC 2028, PB 07 e China Careca revelou aumento de expressão das enzimas do sistema antioxidativo apenas para o acesso China Careca quando comparadas com os normalizadores actina e ubiquitina utilizados no experimento. Para os dois normalizadores foi observado o mesmo padráo de expressão gênica (Figura 1). No entanto, para o normalizador ubiquitina, o gene SOD-Fe não apresentou expressão diferencial quando submetido a déficit hídrico, tendo, nesse caso, maior expressão desse gene no controle negativo (sem PEG $6.00010 \mathrm{~g} \mathrm{~L}^{-1}$ ).

Em situação de déficit hídrico, o acesso China Careca apresentou maior expressão diferencial e aumento de cerca de três vezes no nível de transcrição dos genes SOD-Cu/Zn e expressão 1,7 vez maior para os genes SOD-Mn, CAT e APX (Tabela 2). Contrariamente, o gene SOD-Fe não apresentou expressão diferencial em China Careca, sendo diferentemente mais expresso no controle negativo e nos acessos PB 07 e IAC 2028. O gene CAT foi diferencialmente expresso (1,6 vez) apenas no acesso PB 07. O acesso IAC 2028 não apresentou expressão diferencial em situação de déficit em nenhum dos genes alvo.

Tabela 1. Eficiência de amplificação dos iniciadores pertencentes ao sistema antioxidativo e genes de referência

\begin{tabular}{|c|c|c|}
\hline GENES & SLOP & EFICIÊNCIA \\
\hline CAT & \multirow{4}{*}{$-3,4225$} & \multirow{4}{*}{0,96} \\
\hline D:CCCAGGAGCTGCGCACTAT & & \\
\hline R:GCTAGCTTCTGACCCAGGGATT & & \\
\hline${ }^{*}(\mathrm{X} 59383.1)$ & & \\
\hline APX & \multirow{4}{*}{$-3,3362$} & \multirow{4}{*}{0,99} \\
\hline D:AACTCAGGGTCTTCCAACAAAGC & & \\
\hline R:AACTCAGGGTCTTCCAACAAAGC & & \\
\hline *(T5225.1) & & \\
\hline $\mathrm{SOD}(\mathrm{Cu} / \mathrm{Zn})$ & \multirow{4}{*}{$-3,3417$} & \multirow{4}{*}{0,99} \\
\hline D: AAACCTGTCAAGCCAACCCATA & & \\
\hline R: TGAACTGCTTCTCCAGGAATCC & & \\
\hline${ }^{*}(\mathrm{~T} 15128.1)$ & & \\
\hline SOD (Fe) & \multirow{4}{*}{$-3,4192$} & \multirow{4}{*}{0,96} \\
\hline D: AAACCCCTTTCCCGAATTCA & & \\
\hline R: TGCATGGATTCCCAAAAGAAGT & & \\
\hline *(XM002520869.1) & & \\
\hline SOD (Mn) & \multirow{4}{*}{$-3,2360$} & \multirow{4}{*}{1,03} \\
\hline D:GGGCGACTCTTCTTCTGTTGTTAA & & \\
\hline R: TTGATATGACCTCCTCCGTTGAA & & \\
\hline *(XM002520810.1) & & \\
\hline ACT & \multirow{4}{*}{$-3,0784$} & \multirow{4}{*}{1,11} \\
\hline D: GCCGACGCCGAGGATATT & & \\
\hline R: CCAGCCTTCACCATTCCAGTT & & \\
\hline *(AY360221.1) & & \\
\hline UBQ & \multirow{4}{*}{$-3,3255$} & \multirow{4}{*}{0,99} \\
\hline D:TTCTCATGTGAGGGACTATGGTGTT & & \\
\hline R:CTGAAAGTCTGAGAACCAAATGCA & & \\
\hline *(XM002516651.1) & & \\
\hline
\end{tabular}




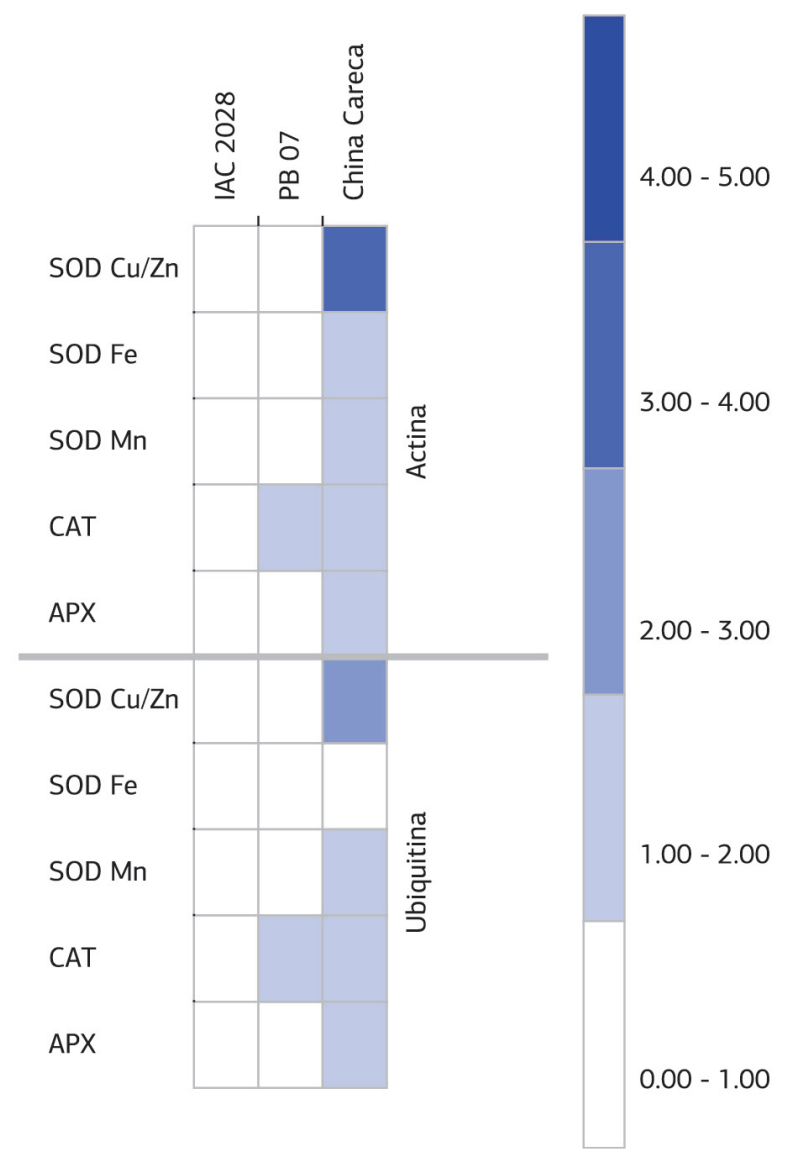

Figura 1. Heat map representando valores médios de expressão diferencial de genes alvos em três acessos de mamona durante 24 horas de déficit hídrico, determinada pela quantitativa PCR em tempo real.

\section{Respostas enzimáticas}

Em situação de déficit hídrico, o acesso China Careca apresentou maior atividade de CAT (média de 0,0013) e maior atividade enzimática da SOD (média de 6,314) quando comparado com PB 07 e IAC 2028, que apresentaram valores inferiores na atividade dessas enzimas (Tabela 3).

$\mathrm{O}$ acesso China Careca apresentou maior atividade de CAT e SOD, porém menor atividade de GPOX. Já o acesso IAC 2028 mostrou maior atividade de GPOX e menor atividade de CAT. Esse mesmo padráo de alternância de atividade enzimática foi verificado no acesso PB 07, que teve uma maior atividade da enzima GPOX, contra uma menor atividade da enzima CAT (Tabela 3).

\section{DISCUSSÃO}

Plantas possuem sistemas enzimáticos de defesa contra espécies reativas de oxigênio, incluindo SOD, CAT, APX. A ativaçáo de genes que codificam essas enzimas em resposta a estresse oxidativo foi observada, também, em tabaco (Bowler et al., 1991), soja (Lee et al.,1999) e amendoim (Sankar et al., 2007).

Estudos com superexpressão das isoformas de SOD demonstram o aumento da tolerância contra as ERO em arroz (Tanaka et al., 1999) e tabaco (Van Breusegem et al., 1999). Como observado no presente trabalho, o acesso

Tabela 2. Valores médios de expressão diferencial (actina e ubiquitina) entre os acessos de mamona para os genes estudados

$\begin{array}{cccc}\text { GENES } & \text { China Careca } & \text { ACESSOS } & \text { PB 07 } \\ \text { IAC 2028 }\end{array}$

Tabela 3. Teste de média das atividades enzimáticas de CAT, APX, GPOX e SOD entre os três acessos avaliados $(\Delta=$ Tratamento - Controle) no tempo de 24 horas

\begin{tabular}{|c|c|c|c|}
\hline ENZIMAS & ACESSOS & MÉDIA* & $5 \%$ ** \\
\hline \multirow[b]{2}{*}{ CAT } & China Careca & 0,0013 & $\mathrm{a}$ \\
\hline & IAC 2028 & 0,0008 & $a b$ \\
\hline \multirow{3}{*}{ APX } & China Careca & 0,1766 & $\mathrm{a}$ \\
\hline & IAC 2028 & 0,1629 & $\mathrm{a}$ \\
\hline & PB 07 & 0,1490 & $\mathrm{a}$ \\
\hline \multirow{3}{*}{ GPOX } & IAC 2028 & 0,0745 & $\mathrm{a}$ \\
\hline & PB 07 & 0,0692 & $\mathrm{a}$ \\
\hline & China Careca & 0,0135 & b \\
\hline \multirow{3}{*}{ SOD } & China Careca & 6,314000 & $\mathrm{a}$ \\
\hline & PB 07 & 4,356000 & $a b$ \\
\hline & IAC 2028 & 4,306000 & $a b$ \\
\hline
\end{tabular}

\footnotetext{
${ }^{*}$ Valores expressos em $\mu \mathrm{mol} \cdot \mathrm{min}^{-1} \cdot \mathrm{mg}^{-1} \mathrm{MF}$; ${ }^{* *}$ Tukey $(\mathrm{p}<0,05)$; médias seguidas por letras distintas diferem entre si.
} 
China Careca apresentou maior expressão de SOD-Cu/Zn e SOD-Mn em resposta ao déficit hídrico causado por PEG.

A superexpressão do gene SOD-Mn foi induzida em plantas de tabaco e foi observado que essa enzima confere tolerância aos danos celulares causados por radical de oxigênio (Bowler et al., 1991). A superexpressão de apenas uma das isoformas de SOD pode ser explicada pela compartimentação das diferentes SOD dentro das células. A isoforma SOD-Cu/Zn é encontrada no citosol (cloroplasto) e possivelmente no espaço extracelular, SOD-Fe está localizada nos cloroplastos e SOD-Mn se localiza nas mitocôndrias (Alscher et al., 2002; Scandalios, 2005). O mesmo padrão de expressão observado em SOD-Fe e SOD-Mn pode ser devido a essas duas isoformas de SOD serem as mais antigas e, possivelmente, terem surgido da mesma enzima ancestral. Apesar de SOD-Cu/Zn possuir similaridade com a sequência de SOD-Fe e SOD-Mn, provavelmente evoluíram separadamente nos eucariotos (Alscher et al., 2002). Isso explica o fato de o gene SOD-Cu/Zn ser três vezes mais expresso na cultivar China Careca, quando comparado com as outras isoformas que tiveram menor expressão.

Foi possível observar um aumento de 80\% e 70\% na expressáo dos genes CAT e APX no acesso China Careca, respectivamente. Em segundo plano foi observado aumento (70\%) na expressão apenas de CAT no acesso PB 07. Ambas as enzimas possuem alta afinidade para peróxido, sendo capazes de detoxificar baixas concentraçóes de $\mathrm{H}_{2} \mathrm{O}_{2}$ (Wang et al., 1999). Segundo Chamnongpol et al. (1998), Lee et al. (1999) e Sankar et al. (2007), essa enzima está diretamente ligada com a resposta a estresses bióticos e abióticos.

O nível de expressão diferencial acima de 1,5 (50\%) observado em China Careca para todos os genes do estudo, com exceção de SOD (Fe), pode estar relacionado com o caráter precocidade desse acesso. Enquanto os acessos IAC 2028 e PB 07 completam o seu ciclo de produção em 180 dias, aproximadamente (nas coordenadas geográficas do município de Campinas, SP), China Careca precisa de apenas 100 dias.

Os resultados obtidos a partir da análise da atividade enzimática corroboram os dados de expressão gênica, tendo o acesso China Careca apresentado maior atividade de CAT e SOD. Assim, o aumento da atividade dessas enzimas está diretamente ligado com a expressão diferencial desses genes pertencentes ao sistema antioxidante, tendo como uma de suas funçóes impedir o acúmulo de $\mathrm{H}_{2} \mathrm{O}_{2}$ nas células (Eyidogan \& Oz, 2007; Vaidyanathan et al., 2003).

\section{CONCLUSÃO}

Os acessos estudados no presente trabalho apresentam características morfológicas que facilitam a sobrevivência e adaptação ao déficit hídrico por serem xerófilas. No entanto, o acesso China Careca apresentou um sistema de defesa contra as ERO mais eficiente, sugerindo ser menos sensível a situaçóes de seca. A confirmaçáo em campo de um sistema mais eficiente de defesa contra as ERO em um acesso mais precoce abre importante perspectiva de trabalho por meio da sua utilização em programas de melhoramento genético visando não apenas à precocidade de produção, como também maior capacidade de resistência a efeitos do déficit hídrico.

\section{REFERÊNCIAS}

Allan, G., Williams, A., Rabinowicz, P. D., Chan, A. P., Ravel, J., \& Keim, P. (2008). Worldwide genotyping of castor bean germplasm (Ricinus communis L.) using AFLPs and SSRs. Genetic Resources and Crop Evolution, 55, 365-378. http://dx.doi.org/10.1007/ s10722-007-9244-3.

Alscher, R. G., Erturk, N., \& Heath, L. S. (2002). Role of superoxide dismutases (SODs) in controlling oxidative stress in plants. Journal of Experimental Botany, 53, 1331-1341. http://dx.doi.org/10.1093/ jexbot/53.372.1331. PMid:11997379

Amako, K., Chen, G.-X., \& Asada, K. (1994). Separate assays specific for ascorbate peroxidase and guaiacol peroxidase and for the chloroplastic and cytosolic isozymes of ascorbate peroxidase in plants. Plant \& Cell Physiology, 35, 497-504.

Atsmon, D. (1989). Castor. In G. Robbelen, R. K. Downey, \& A. Ashri (Eds.), Oil crops of the world their breeding and utilization (p. 438-447). New York: McGraw-Hill.

Beever, D. (2000). Os transgênicos e o futuro da agricultura. Biotecnologia e Desenvolvimento., 15, 4-7.

Bowler, C., Slooten, L., Vandenbranden, S., De Rycke, R., Botterman, J., Sybesma, C., Van Montagu, M., \& Inzé, D. (1991). Manganese superoxide dismutase can reduce cellular damage mediated by oxygen radicals in transgenic plants. The EMBO Journal, 10, 1723-1732. PMid:2050109.

Brigham, R. D. (1967). Natural outcrossing in dwarf-internode castor bean, Ricinus communis L. Crop Science, 7, 353-355. http://dx.doi. org/10.2135/cropsci1967.0011183X000700040022x.

Casagrande, E. C., Farias, J. R. B., Neumaier, N., Oya, T., Pedroso, J., Martins, P. K., Breton, M. C., \& Nepomuceno, A. L. (2001). Expressão gênica diferencial durante déficit hídrico em soja. Revista Brasileira de Fisiologia Vegetal, 13, 168-184. http://dx.doi.org/10.1590/ S0103-31312001000200006.

Chamnongpol, S., Willekens, H., Moeder, W., Langebartels, C., Sandermann, H. Jr, Van Montagu, M., Inzé, D., \& Van Camp, W. (1998). Defense activation and enhanced pathogen tolerance induced by $\mathrm{H} 2 \mathrm{O} 2$ in transgenic tobacco. Proceedings of the National Academy of Sciences of the United States of America, 95, 5818-5823. http:// dx.doi.org/10.1073/pnas.95.10.5818. PMid:9576968

Costa, P. H. A., Azevedo-Neto, A. D., Bezerra, M. A., Prisco, J. T., \& Gomes-Filho, E. (2005). Antioxidant-enzymatic system of two sorghum genotypes differing in salt tolerance. Brazilian Journal of Plant Physiology, 14, 353-361. 
Elliott, J., Glotter, M., Best, N., Boote, K. J., Jones, J. W., Hatfield, J. L., Rosenzweig, C., Smith, L., \& Foster, I. (2013). Predicting agricultural impacts of large-scale drought: 2012 and the case for better modeling. Center for Robust Decision Making on Climate \& Energy Policy (RDCEP) Working Paper Series, 1-8.

Eyidogan, F., \& Oz, M. T. (2007). Effect of salinity on antioxidant responses of chickpea seedlings. Acta Physiologiae Plantarum, 29, 485-493. http://dx.doi.org/10.1007/s11738-007-0059-9.

Fan, X. W., Li, F. M., Song, L., Xiong, Y. C., An, L. Z., Jia, Y., \& Fang, X. W. (2009). Defense strategy of old and modern spring wheat varieties during soil drying. Physiologia Plantarum, 136, 310-323. http://dx.doi.org/10.1111/j.1399-3054.2009.01225.x. PMid:19453498

Figueiredo, A., No., Almeida, F. A. C., Gouveia, J. P. G., Nóbrega, M. B. M., Carneiro, R. M., \& Pedroza, J. P. (2004). Divergência genética em acessos de mamona (Ricinus communis L.) baseada nas características das sementes. Revista de Biologia e Ciências da Terra, 4, 2.

Gupta, S., Webb, A. R. P., Holaday, A. S., \& Allen, R. D. (1993). Over-expression of superoxide dismutase protects plants from oxidative stress: Induction of ascorbate peroxidase in SED over-expressing plants. Plant Physiology, 103, 1067-1073.

Jaleel, C. A., Manivannan, P., Sankar, B., Kishorekumar, A., Gopi, R., Somasundaram, R., \& Panneerselvam, R. (2007). Water deficit stress mitigation by calcium chloride in Catharanthus roseus: effects on oxidative stress, proline metabolism and indole alkaloid accumulation. Colloids and Surfaces. B, Biointerfaces, 60, 110-116. http://dx.doi. org/10.1016/j.colsurfb.2007.06.006. PMid:17643271

Jambunathan, N. (2010). Determination and detection of reactive oxygen species (ROS), lipid peroxidation, and electrolyte leakage in plants. Methods in Molecular Biology (Clifton, N.J.), 639, 291-297. http://dx.doi.org/10.1007/978-1-60761-702-0_18. PMid:20387054

Jebara, S., Jebara, M., Limam, F., \& Aouani, M. E. (2005). Changes in ascorbate peroxidase, catalase, guaiacol peroxidase and superoxide dismutase activities in common bean (Phaseolus vulgaris) nodules under salt stress. Journal of Plant Physiology, 162, 929-936. http:// dx.doi.org/10.1016/j.jplph.2004.10.005. PMid:16146319

Joachimiak, M. P., Weisman, J. L., \& May, B. Ch. (2006). JColorGrid: software for the visualization of biological measurements. BMC Bioinformatics, 7, 225. http://dx.doi.org/10.1186/1471-2105-7225. PMid:16640789

Lee, S. C., Kang, B. G., \& Oh, S. E. (1999). Induction of ascorbate peroxidase by ethylene and hydrogen peroxide during growth of cultured soybean cells. Molecules and Cells, 9, 166-171. PMid:10340471.

Livak, K. J., \& Schmittgen, T. D. (2001). Analysis of relative gene expression data using real time quantitative PCR and the 2- $\Delta \Delta \mathrm{CT}$. Methods, 25, 402-408.

Meneses, C. H. S. G., Lima, L. H. G. M., Lima, M. M. A., \& Vidal, M. S. (2006). Aspectos genéticos e moleculares de plantas submetidas ao déficit hídrico. Revista Brasileira de Oleaginosas e Fibrosas, 10, 1039-1072.

Morgante, C. V., Guimarães, P. M., Martins, A. C. Q., Araújo, A. C. G., Leal-Bertioli, S. C., Bertioli, D. J., \& Brasileiro, A. C. M. (2011). Reference genes for quantitative reverse transcription-polymerase chain reaction expression studies in wild and cultivated peanut. BMC Research Notes, 4, 339. http://dx.doi.org/10.1186/1756-0500-4-339. PMid:21906295
Ogunniyi, D. S. (2006). Castor oil: a vital industrial raw material. Bioresource Technology, 97, 1086-1091. http://dx.doi.org/10.1016/j. biortech.2005.03.028. PMid:15919203

Pfaffl, M. W. (2001). A new mathematical model for relative quantification in real-time RT-PCR. Nucleic Acids Research, 29, 2002-2007.

R Development Core Team (2011). R: Á language and environment for statistical computing. Vienna: R Foundatin for Statistical Computing.

Rozen, S., \& Skaletsky, H. (2000). Primer3 on the WWW for general users and for biologist programmers. In S. Krawetz, \& S. Misener (Eds.), Bioinformatics methods and protocols: methods in molecular biology (p. 365-386). Totowa: Humana Press.

Sankar, B., Jaleel, C. A., Manivannan, P., Kishorekumar, A., Somasundaram, R., \& Panneerselvam, R. (2007). Effect of paclobutrazol on water stress amelioration through antioxidants and free radical scavenging enzymes in Arachis hypogaea L. Colloids and Surfaces. B, Biointerfaces, 60, 229-235. http://dx.doi.org/10.1016/j.colsurfb.2007.06.016. PMid:17764913

Scandalios, J. G. (2005). Oxidative stress: molecular perception and transduction of signals triggering antioxidant gene defenses. Brazilian Journal of Medical and Biological Research = Revista brasileira de pesquisas médicas e biológicas/Sociedade Brasileira de Biofísica..., 38, 995-1014. http://dx.doi.org/10.1590/S0100-879X2005000700003. PMid:16007271

Silva, A. A., \& Gonçalves, R. C. (2010). Espécies reativas do oxigênio e as doenças respiratórias em grandes animais. Ciência Rural., 40, 994-1002. http://dx.doi.org/10.1590/S0103-84782010005000037.

Silva, H. A. P., Galisa, P. S., Oliveira, R. S. S., Vidal, M. S., \& SimóesAraujo, J. L. (2012). Gene expression induced by abiotic stress in cowpea nodules. Pesquisa Agropecuária Brasileira, 47, 797-807.

Souza, A. S., Tavora, F. J. A. F., Pitombeira, J. B., \& Bezerra, F. M. (2007). Épocas de plantio e manejo da irrigação para a mamoneira. II - crescimento de produtividade. Revista Ciência Agronômica, 38, 422-429.

Sujatha, M., Reddy, T. P., \& Mahasi, M. J. (2008). Role of biotechnological interventions in the improvement of castor (Ricinus communis L.) and Jatropha curcas L. Biotechnology Advances, 26, 424-435. http:// dx.doi.org/10.1016/j.biotechadv.2008.05.004. PMid:18579331

Tanaka, Y., Hibino, T., Hayashi, Y., Tanaka, A., Kishitani, S., Takabe, T., Yokota, S., \& Takabe, T. (1999). Salt tolerance of transgenic rice overexpressing yeast mitochondrial Mn-SOD in chloroplasts. Plant Science, 148, 131-138. http://dx.doi.org/10.1016/S01689452(99)00133-8.

Vaidyanathan, H., Sivakumar, P., Chakrabarty, R., \& Thomas, G. (2003). Scavenging of reactive oxygen species in $\mathrm{NaCl}$-stressed rice (Oryza sativa L.) - Differential response in salt-tolerant and sensitive varieties. Plant Science, 165, 1411-1418. http://dx.doi.org/10.1016/j. plantsci.2003.08.005.

Van Breusegem, F., Slooten, L., Stassart, J. M., Botterman, J., Moens, T., Van Montagu, M., \& Inze, D. (1999). Effects of overproduction of tobacco MnSOD in maize chloroplasts on foliar tolerance to cold and oxidative stress. Journal of Experimental Botany, 50, 71-78. http://dx.doi.org/10.1093/jxb/50.330.71. 
Wang, J., Zhang, H., \& Allen, R. D. (1999). Overexpression of an Arabidopsis peroxisomal ascorbate peroxidase gene in tobacco increases protection against oxidative stress. Plant \& Cell Physiology, 40, 725-732. http://dx.doi.org/10.1093/oxfordjournals.pcp.a029599. PMid:10501032
Weiss, E. A. (1971). Castor bean, Sesame, and safflower. London: Leonard Hill.

Weiss, E. A. (1983). Oilseed crops. London: Longman.

Weiss, E. A. (2000). Oilseed crops. London: Blackwell Science. 